\title{
Impact of English Language Teaching and Learning through Language Laboratory in Engineering in Nepal
}

\author{
Rup Narayan Shrestha ${ }^{1}$, Bharat Pahari ${ }^{2}$, Jai Raj Awasti ${ }^{3}$ \\ ${ }^{1}$ Department of Engineering Science and Humanities, Central Campus, Pulchowk, IOE, TU, Lalitpur, Nepal \\ ${ }^{2}$ Institute of Engineering, Tribhuvan University, Pulchowk, Lalitpur, Nepal \\ ${ }^{3}$ Far-western University, Nepal \\ Corresponding Email: rupnarayan_sth@hotmail.com
}

\begin{abstract}
The present article discusses the importance of language, in general, and English, in particular, in the context of engineering education in Nepal. It mainly discusses the importance and application of language laboratory for the enhancement of skills and proficiency of English language in the learners of Bachelor's level in engineering in Nepal. The main objective of the present article is to highlight the importance of teaching and learning of English language in the B.E. level in engineering by using language laboratory. In course of the present study, literature available in different accessible sources was reviewed for collecting necessary data and designing theoretical framework for the same. From the study, it has been found that language laboratory is tremendously helpful in creating favourable atmoshphere for language learning and helping the learners to acquire necessary language skills useful to them in sharpening their study at present and streamlining their research and innovative activities in their further studies in the future. English language is now the language of worldwide communication, and therefore, it is very essential for the students of engineering to be proficient in communication through English not only for grabbing job opportunities open at present but also to furthering their future research and innovative endeavors and publishing their reports and research articles based on them. Language Laboratory is highly instrumental for attaining ample proficiency in English language, the means of global communication.
\end{abstract}

Keywords: Language, teaching, learning, communication, engineering, science, technology, computer, language laboratory

\section{Introduction}

Language is the only means of human communication. Being social animals, human beings find it quite impossible to survive without language which enables them to share experiences, thoughts, feelings, and ideas. It is due to the ability to speak language that human beings have proved themselves superior beings in the whole universe to the other creatures and have attained such an incomparable achievement in science and technology as well as in civilization.

English language, one of the most advanced languages in the world with the widest circulation, has emerged as the most influential language in the modern world. English is used as a medium of communication in diverse fields e.g. tourism, trade and technology, research and innovation. In education, English has occupied a really significant position all over the world. It is used as a medium of instruction in the classroom and as a medium of expression in the examination. It is also used for note taking and library consultation, e-mail and internet access.

In science and technology, English language serves a great deal of purposes. It enables people to share the innovations and explorations made by them in science and technology through their 
publications such as journals, reports, articles and papers. Engineering education is not an exception to this fact. English occupies a very important space in the curriculum in engineering upto Bachelor's level in Nepal. It has been broadly realized that there is no alternative means of communication that can replace English in the present context and it is equally evident that it is likely to remain unchallenged until remote future unless the experts of curriculum designing grow maopic in vision. For sharpening the learners' language skills through constant practice, language laboratory in highly effective and instrumental.

\section{Literature Review}

\section{Language as a means of Human Communication}

Speaking a language is one of the fundamental characteristics of human beings. It is this characteristic which has enabled human beings to prove themselves the most advanced and creative beings. Unlike other creatures, human beings communicate with each other with a special system of communication known as language which has been defined variously by various linguists.

According to - H.G. Widdowson (2003) Language certainly figures centrally in our lives. We discover our identity as individuals and social beings when we acquire it during childhood, it serves as a means of cognition and communication; it enables us to think for ourselves and to cooperate with other people in our community. It provides for present needs and future plans and at the same time carries with it the impression of things past.

Language serves not only as a means of exchanging ideas, thoughts, feelings and experiences but also as a tool for executing our duties. No matter whatever sort of job we have, we must use language for convincing others. We do so through reading, writing or speaking which are known as the receptive and productive skills in language requiring extra effort and constant practice for the improvement in communicative skills.

Widdowson (2003) adds further that Language is something we 'know' we ask someone if he 'knows' French or German, or if he 'Knows' some word or other. It is also something we 'do', we 'write, read, speak well or badly. In this case, we are treating it as skilled behavior which we have to learn, and improves through practice.

The skill in using language justifies how advanced or backward the user is. The way one speaks a language helps his audience to generalize his social status. The speaker is judged on the basis of how skillfully he uses a language.

H.G. Widdowson has rightly remarked that language seems to be 'a feature of our essential humanity which enables us to rise above the conditions of mere brutish beings, real or imagined.' Shakerpeare's Caliban in The Tempest 'gabbles like a thing most brutish' until Prospero teaches him language. In the play, he is referred to as a monster.

\section{English as a World Language}

Among various languages, English has earned the highest popularity all over the world. Because of its great its popularity and worldwide invasion, English has the pre-eminent claim to be the medium of international communication (Baruah 1984). 


\section{Importance of English in the present day world}

English language enables people of all walks of life to express desires and to publish the scholarly thoughts worldwide. Baruah (1984) adds, "if a person knows English, he is sure to be understood anywhere in the world. With the tremendous advance in modern transport and communication systems, the world is growing smaller and smaller."

\section{English Language in Nepal}

The influence of English language in the education system in Nepal is very great. English was introduced in the Nepalese education more than one and a half centuries ago by the then Rana rulers to make their children able to use English in their day to day life. But later on, even the children of commoners in Nepal were allowed to have an access to English education. English was incorporated in the school level as well as college level curriculum. English began to be taught as one of the compulsory subjects upto bachelor's level. It happened as a result of the realization of the importance of English. Even today, English is being taught as a compulsory subject upto Bachelor's level.

\section{English Language in Science and Technology}

English language is felt to be equally important and relevant in the field of science and technology. We have not yet been self-sufficient in this field in textbooks and many other reference materials that our students need. Not only for acquiring the necessary information, but also for publishing their research findings and innovations, they feel themselves handicapped without English proficiency.

\section{English Language Teaching (ELT) in Engineering in Nepal}

Keeping the ever increasing importance and relevance of English in the present context in mind, English is being taught as a compulsory subject in the Bachelor's level of Engineering in Tribhuvan University from the very inception. In the recently designed syllabus of compulsory English for Bachelor's of Engineering, which is believed to be more compact and comprehensive, the four basic skills of language: listening, speaking, reading and writing have been given ample space.

\section{Importance of Teaching Listening and Speaking Skills in B.E.}

Language learning involves learning the four basic skills known as listening, speaking, reading and writing. These four skills are often grouped under two major language skills called receptive skill and productive skill. In the natural process of language acquisition and learning, listening skill is believed to be the most fundamental and important skill on which the development of other language skills is based. In the opinion of Sangeeta Sharma and Binod Mishra (2010), 'listening is an important ingredient of learning' Before a child learns to write alphabets, he learns sounds and words. This is possible because of listening. The same is true of many people who don't know how to write in a particular language but can speak it as effectively as a native speaker. Linguists also believe that ' language is not taught but caught.'

Without listening, no other language skills can be expected to be acquired efficiently and perfectly by any language learner. In the words of Ronald Carter and David Nunan (2001), 
'listening is not only a skill in the area of language performance, but also a crucial means of acquiring' a second language (12). In their view, 'listening is the channel in which we process language in real time employing pacing, units of encoding and pausing that are unique to spoken language.

Speaking skill develops as a result of listening. David Cross (1992) remarks that "fluent speech ... is a product not a practice in speaking, but of participation in receptive activities. The primacy of listening competence in interaction is evident to engage in any form of communication." Emphasing on the importance of listening in the development of speech, Jeremy Harmer (1999) states, "In order to develop Communicative efficiency in pronunciation, the students need to understand how sounds are made and how stress is used."

English Language Teaching (ELT) in Engineering under Tribhuvan University (T.U.) is not a novel programme in the context of Nepal. It was incorporated as a compulsory subject right from the inception. However, there has been a revolutionary change in the course of compulsory English for Bachelor's Level of Engineering (B.E.) in T.U. recently. In place of two papers of English course carrying 50 marks each, there has been a single paper of compulsory English carrying 125 marks out of which the theoretical aspect of the course which comprises teaching of reading and writing skills carries 100 marks whereas the practical aspect of the course comprising listening and speaking skills to be practised in language laboratory carries 25 marks.

\section{The Language Laboratory}

Seaton (1982) defines language laboratory as a classroom ... containing electronic and mechanical equipment' designed and arranged to make foreign languages learning easier than is usually possible without it. Geeta Nagaraj (1996) describes that language laboratory consists of a system which makes use of tape recorders to provide individualized language learning facilities. A typical language laboratory has booths with tape recorders. These records generally have \begin{tabular}{|l|l|l|l|}
\hline ON & STOP OFF REWIND and RECORD mechanism. The 'master' recording, which
\end{tabular} enables a learner to listen on one track and record' on the others, is provided in each booth. These booths are connected to a monitor control panel. The teacher supervising the language laboratory session can plug into any of the booths to listen in and provide help when and if required. Learners listen in individual booths and do the tasks required.

\section{Importance of Language Laboratory}

According to J. Dakin (1973), the laboratory offers certain facilities which can not be reproduced' in the classroom. The facilities are most fully exemplified in a laboratory in which every student has his own tape recorder. The tape recorder is equipped with earphones which enables the learner to listen to the material recorded on his own tape without disturbing the rest of the class. Through a microphone, he can also record his own voice. He can play back his recording to check for mistake or to compare his own efforts with a model version already recorded on the tape. There is a connecting channel between the teacher and the learner so that the former can listen to what the learner is doing and discuss any problems with without interrupting the work of other learners.

When these aids are properly integrated into the course work, they give a unique dimension to teaching. For the average mixed adult class, where understanding and responding in basic 
linguistic situations is likely to be a primary aim, these aids provide a realistic stimulus for oral and aural activities (Brian Hill and Edith Baer 1995).

Prof. R.N. Khanal (2012) claims 'in language labs students can have real exposure to the communication. They will really be involved in learning the techniques of communication with the use of their basic level of English language. The teacher can play the role of facilitator then.'

\section{Practical Application of Language Lab}

Though the concept of Language Laboratory is not a new one, it still has some relevance in the field of language teaching. Language teaching and learning are practical skill-based activities. To develop the four language skills namely listening, speaking, reading and writing in the learners to a desired extent, the importance of language laboratory can not be ignored. For teaching and learning language effectively, Language Laboratory can be used for the following practice-oriented activities:
a) CALL (Computer Assisted Language Learning)
b) Pronunciation
c) Presentations
d) Interview
e) Group Discussions
f) Debates
g) Public Speaking
h) Role Play

\section{a) CALL}

Computer Assisted Language Learning (CALL) is one of the latest techniques developed for the effective teaching and learning of language especially in the field of second or foreign language teaching and learning. For the effective implementation and execution of CALL language laboratory or Computer laboratory is a most essential pre-requisite. CALL requires computer laboratory with or without teacher attending and guiding the students. Students themselves also can work independently.

\section{b) Pronunciation}

Pronunciation is one of the most important aspects of language learning process. Pronunciation is associated with spoken or oral form of language. The process of language learning especially the learning of foreign language learning cannot be complete without the proper control or mastery over the pronunciation.

\section{c) Presentation}

As mentioned by E. Suresh Kumar and P. Sreehari (2007), 'a presentation is a purposeful communication. In other words, it is the process of presenting a topic to an audience, with a specific purpose.' In the modern age of communication highway, every one makes presentation for making one's oneself successful in one's respective field. No matter whatever field we might 
belong to everyone of us needs to be proficient enough in making presentation. A student, a teacher as well as a businessman all should be good enough in making presentation for proving ourselves to be effective in their respective fields.

Tips for making presentation:

- Choose the right topic

- Have a clear goal

- Have a central idea or thesis

- Know your audience

- Know the venue

- Know the time and length of presentation

- Decide on the methodology

- Structure your presentation

- Plan ahead

- Learn to use technology

- Cope with stage fright

- Make effective use of non-verbal communication

- Rehearse your presentation

\section{d) Interview}

Interview is one of the activities that can be held in an artificial setting making the students or participants pretend themselves to be an interviewer or an interviewee or by making them play the roles of a journalist and one of the reputed personalities in the town or the country.

Tips for making the interviewer effective

- Do your research

- Look Professional

- Be on time

- Do think of ways to connect your past experiences to the job you are applying for

- Maintain eye contact

- Ask questions

- Be active and show your interest in the interview

- Be focused

- Keep eye contact with the interviewer(s)

- Use simple and clear words

- Express your views slowly and steadily

- Make use of gestures

- Don't forget to be yourself

- Don't be negative in your attitude

- Don't forget to thank the panel 


\section{e) Group Discussion}

As E. Suresh Kumar and P. Sreehari (2007) put it, "A group discussion (GD) is a type of interactive, oral communication which takes place when a group of people get together to discuss something." A group discussion can be held in both formal and informal setting. As a group discussion offers each participant an opportunity to express his/her experiences, thoughts and feelings about the topic or issue being discussed in the group, there is a trend of using it as a tool to identify and select candidates with the right ability.

Tips for good group discussion:

- Understand the topic given clearly and correctly

- Be cheerful

- Stay active

- Be willing to listen

- Be focused and do not allow your mind to wander about

- Speak to the whole group

- Substantiate your views

- Speak in an understandable way

- Express your views slowly and steadily

- Be polite, friendly and acceptable

- Be considerate to others

- Do not feel that you are superior to others.

- Do not be emotional

- Do not be shy and hesitant

- Do not make your points repetitive

- Do not dominate or monopolise the discussion

\section{f) Debates}

Longman Dictionary of Contemporary English (1995) defines debate as "a formal discussion on a subject." when we look at the term 'debate' superficially and try to decipher its literal meaning, it sounds like an argument or discussion that takes place between the two individuals or groups of people who are quarrelling. But debate, in the simple sense, refers to the exchange of thoughts of ideas that takes place between two groups or individuals. In the words or E. Suresh Kumar and P. Sreehari (2007), 'debate or debating is a method of interactive argument." Debate may also be one of the events that can be organized regularly in a language laboratory for the purpose of improving and enhancing the learners' language skills.

Essentials of debate:

- Content

- Use examples

- Have unity

- Structure your content 
- Use clear links

- Eye contact

- Voice

- Gestures

- Enunciation

- Clarity

\section{g) Public speaking}

As defined in the Longman Dictionary of contemporary English (1995); 'Public speaking' refers to 'the activity of making speeches in public.' According to E. Suresh Kumar and P. Sreehari (2007), "Public speaking is a form of communication in which the speakers speak to a group of people with a view to sharing his/her ideas/thoughts on a topic." To them, public speaking is 'both an art and a science" (2007).

Public speaking can be included in the language activities to be conducted in language laboratory. It is extremely helpful and effective in developing the desired extent of speaking skills in the young learners. Through the constant practice of public speaking, they can rid themselves of the fear of the public and be bold enough for presenting their views in the public.

Essentials of an effective speech:

- Prepare well

- Use examples and personal experiences

- Use humour sparingly

- Surprise or shock your audience

- Make it purposeful

- Be active and energetic

- Use gestures

- Use pouses effectively

- Vary your tone

- Make eye contact

- Regulate your breath

- Rehearse the whole speech

\section{h) Role Play}

'Role play' can be one of the effective language activities to be included in the list of different things to be done by the learners in the languages laboratory. Apart from of listening to the audio cassettes, watching videos or movies and reading, writing and speaking, the learner may occasionally be given different roles to play. The roles people take up during a discussion can be divided into task roles, building roles, maintenance and negative roles (Sunita Mishra and C. Muralikrishna /2004).

Things to be borne in mind: 
- What are you trying to do with your language?

- What sort of a person are you in a particular situation?

- What is the setting of the role play?

- What are you talking about?

\section{Conclusion}

Language serves a great deal of communication purpose in every sphere of human civilization. As a tool of communicating thoughts, experiences and feelings, it has made it possible for human beings not only to fulfil their everyday needs but also to survive in this world of great complexity.

Of all the languages present in the modern world, English has emerged as one of the common languages all over the world with broader access. It has surpassed all the languages in the field of worldwide communication. People living in every nook and corner of the modern World, have begun to feel an urge for learning it as they find it almost impossible to survive without the proficiency in this language.

People of all walks of life need this language. From an ordinary manual labourer to a highly renowned scientist they feel the necessity for making themselves proficient in this language a like.

In the academic field, English is a must. Without English nothing can be learnt and done in the present context. Realizing this fast growing demand and urgency of English as a global language, the planners of our academia have incorporated English as one of the compulsory subjects of teaching and learning from the very pre-primary level to university level.

In the field of Engineering education in Nepal also, English has been incorporated in the courses upto Bachelor's level. Even in the syllabuses designed just a few years ago, English course carrying 125 marks has been devised for B.E level. Out of 125 full marks, 100 marks has been allocated to theoretical aspect comprising reading and writing skills, which are dealt with in the general classrooms and 25 marks have been allocated to the practical aspect comprising listening and speaking which are practised in the language laboratory.

The importance of language laboratory can not be ignored in the teaching of a language like English which has already attained its status not only as a foreign language but also as a global or world language. For the students of Bachelor level of Engineering, English language serves a great deal of purpose. They need it for acquiring sufficient information, data and details through various books, journals, reports, research articles/papers and internet websites during their students life. Even after they complete their courses and want to move ahead in their further academic enhancement, they need English. For publishing their academic as well as research outcomes also they feel the dire need of English proficiency. language laboratory can play a vital role in the enhancement of English language proficiency of the learners of this level. 


\section{References}

[1] Adhikari, Usha ; yadav, Rajkumar ; Shrestha, Rup Narayan ; (2000): Communicative Skills in English, Research Training Unit, IOE, Pulchowk Campus.

[2] Adhikari, Usha, Yadav, Raj Kumar; Shrestha, Rup Narayan; (2012) Technical Communication in English, Trinity Publication, Kathmandu.

[3] Khanal, R.N., (2008) : Need-based Language Teaching (Analysis in Relation to Teaching of English for Profession Oriented Learners) Kathmandu : D. Khanal.

[4] Khanal, R.N. (2012), Technical Communication in English, Kathmandu : D. Khanal.

[5] Konar, Nira (2010), Communication Skills for Professional PHI Learning Private Limited, New Delhi.

[6] Kumar, Ranjit (2006), Research Methodology, Pearson Education.

[7] Laxminarayan, K.R. (2001), English for Technical Communication. Chennai; Scitech publications (India) Pvt. Ltd.

[8] Malla, K.P. (1977) English in Nepalese Education. Ratna Pustak Bhandar, Kathmandu.

[9] Mishra, Sunita et. al. (2004). Communication Skills for Engineers. Pearson Education, First Indian Print.

[10] Prasad, P.et.al (2007), The Functional Aspects of Communication Skills. S.K. Kataria \& sons.

[11] Reinking A James et. al (1999), Strategies for Successful Writing: A rhetoric, researc guide, reader and handbook, Prentice Hall Upper Saddle River, New Jersey.

[12] Rizvi, M. Ashrag (2008), Effective Technical Communication. Tata Mc Graw Hill.

[13] Rutheroford, Andrea J. Ph.D (2001), Basic Communication Skills for Technology, Pearson Education Asia.

[14] Sharma R.C. et al. (2009), Business Correspondence and Report Writing : A Practical Approach to Business and Technical Communication. Tata Mc Graw Hill.

[15] Sharma, Sangeeta et. al (2010) Communication Skills for Engineers and Scientists, PHI Learning Private Limited, New Delhi.

[16] Taylor, Shirley, et. al (2009), Model Business letters, E-mails \& other Business documents, Pearson Education.

[17] Mishra, Sunita; Muralikrishna, C. (2004). Communication Skills for Engineers. Singapore, Pearson Education.

[18] Kumar, Suresh E; Sreehari, P. (2007). A Handbook for English Language Laboratories; New Delhi, Cambridge University Press India Pvt. Ltd.

[19] Previous and the current syllabi of IOE. 